\title{
Impact of Oral Contraceptive Pills (LDs) and Condoms on Women's Sexual Function: A Prospective Study in Iran
}

\author{
Minoo Pakgohar ${ }^{1, *}$, Samira Malekian ${ }^{2}$ \\ ${ }^{1}$ Department of Reproductive Health, Geriatric Nursing, School of Nursing and Midwifery, Tehran University of \\ Medical Sciences, Iran \\ ${ }^{2}$ Department of Nursing and Midwifery, Arak branch, Islamic Azad University, Iran
}

Copyright (C) 2015 Horizon Research Publishing All rights reserved.

\begin{abstract}
Introduction: Female sexual function may be affected by negative or positive effects of contraceptive methods, which needs more investigation. The aim of this study was to determine the impact of low dose oral contraceptive pills (OCPs, LD) and condoms on female sexual function. Material \& Methods: A sample of 62 Iranian women, who were first time users of OCPs, LD $(n=32)$ and condoms $(n=30)$ were assigned for the study. The women's sexual function was assessed using a standard questionnaire both before and four months after using the contraceptive methods. Results: In the OCPs, LD group, there was a significant increase in total sexual function score $(p<0.001)$ and the four domains of sexual function (desire, arousal, orgasm, and satisfaction) four months after the recruitment. In the condom group a significant reduction was found in the five domains as well as the total sexual function score $(\mathrm{p}<0.001)$ four months after recruitment. Conclusion: The results of this study indicated an improvement in sexual function after using OCPs, LD and a significant negative effect on women's sexual function with the use of condoms.
\end{abstract}

Keywords Contraceptive Method, Oral Contraceptive Pills, Condom, Female Sexual Function

\section{Introduction}

Sexual function is an important part of health, quality of life and general well-being and is a complement part that can affect humans from birth to death $[1,2]$. According to the Epidemiologic study in 60 countries in the world, at least 40-45 percent of adult women have a manifestation of sexual dysfunction [3]. The prevalence of female sexual dysfunction in Iranian women is around 31.5 percent [4]. Impaired quality of life, psychological problems and divorce are some adverse effects of sexual dysfunction which is a taboo subject in many countries [4] including Iran. The main key for maintaining normal sexuality is to determine contributing factors of sexual dysfunction [5]. It is expected that oral contraceptive pills affect female sexual function as they have an impact on the level of sex hormones. Theoretically, sexual desire can be decreased following the use of OCPs due to a decrease in the level of bioavailable testosterone [6]. However, there exist conflicting results including positive, negative, and no effects of OCPs on female sexual function [6,7, and 8].

Several researchers have reported that intercourse frequency, sexual pleasure and excitement have been increased in OCP users $[9,10]$. Additionally, in another study among 523 current OCP users, 44 percent of participants reported positive effects on their sexuality [11]. On the contrary, results of another study showed that there is a decrease in sexual desire, frequency and excitement three and nine months after using OCPs. While in Reymond et.al.'s study, there was no impact on sexual function $[12,13]$. It is expected that 80 percent of women have used OCPs at least one time in their life $[14,15]$ as they are the most applicable methods of family planning [16].

The use of condoms is increasing all around the world. Condom acts as a prevention method for STDs and further provides a means to practice safe sex. Additionally, condoms can be used with or without other contraception. Unlike OCPs, condoms have no effect on women's body testosterone and menstrual cycles. However, the negative impacts of condom on coital frequency and orgasm has been reported $[11,17]$.

OCPs as a hormonal contraceptive was the first prevalent effective contraception in Iran. Nonetheless, condom use as a non-hormonal contraception is increasing in Iran. Regarding the controversial results on the impact of OCPs on sexual function, and the scarce data concerning condom effects on sexual function particularly in the Iranian population, it is useful to compare the influence of 
OCP and condoms on Iranian women's sexual function. Thus, this prospective study planned to fill these gaps and complete the relevant information.

\section{Materials \& Methods}

\subsection{Subject Recruitment}

In this prospective study, 62 women of reproductive age (26.78 \pm 4.61$)$ were recruited. Participants were selected by convenience sampling from five family planning centres in the city of Tehran. The women were first time users of low dose oral contraceptive pills OCPs, LD $(n=32)$ and condoms $(\mathrm{n}=30)$. In the current study, (OCPs, LD) with $30 \mu \mathrm{g}$ Ethinylestradiol and $150 \mu \mathrm{g}$ Levonorgestrol were used by the participants.

The exclusion criteria of the study consisted of the following: Pregnancy delivery within the recent six months, irregular menstrual cycles, physical and psychological problems, drug, alcohol and/or cigarette addiction, and medication use that can affect sexual function.

Data was collected using a Persian version of female sexual function index [19] both before and four months after the use of the contraceptive methods. Written consent was obtained from all participants and the Ethic Committee of Tehran University of Medical Science approved the study. Data was analysed by the Wilcoxon test and Mann-Whitney $\mathrm{U}$ test considering $\mathrm{p}$ value less than 0.05 .

\section{Results}

\subsection{Subject Characteristics}

The mean age of participants was $27.46 \pm 4.5$ in OCPs LD and 26.1 \pm 4.64 in condom group with a range of 20-30 years. Most of the participants were not employed with a marital age range of 18-24 years without previous marriage history. The range of participant's partners' age was 25-35 years and most of them were employed without previous marriage experience. The mean duration of marriage was $7.55 \pm 4.98$ in OCPs LD and 5.5 \pm 4.54 in condom group.

\subsection{Sexual Function Measures}

The female sexual function was measured using six FSFI domains: desire, arousal (excitement), lubrication, orgasm, satisfaction and pain during sexual intercourse. The FSFI domain scores were compared using the Wilcoxon test in each group both before and after the use of the contraceptives.

Comparison of FSFI domain scores at recruitment and follow up within the groups is shown in table1. In the OCPs LD group there was a significant improvement in total sexual function score and four FSFI domains scores $(\mathrm{p}<0.001)$. However, lubrication domain was reduced $(\mathrm{p}<0.001)$, and there was no significant difference in pain domain score $(p=0.226)$ In the condom group, there was a significant reduction in four domains as well as the total scores $(p<0.001)$. Similar to the OCP group, the pain domain score in the condom group revealed no change $(\mathrm{p}=0.071$. However, lubrication domain was increased $(\mathrm{p}<0.046)$.

Table 1. Sexual function scores [mean (sd)] at recruitment and 4 months follow up

\begin{tabular}{|c|c|c|c|}
\hline & $\begin{array}{c}\text { At } \\
\text { Recruitment }\end{array}$ & $\begin{array}{l}\text { At } 4 \text { months } \\
\text { Follow-up }\end{array}$ & P-Value \\
\hline \multicolumn{4}{|l|}{ OCP Group } \\
\hline 1.Desire & $2.99(0.93)$ & $3.83(0.74)$ & $<0.001 *$ \\
\hline 2.Arousal & $3.49(1.41)$ & $4.11(1.03)$ & $<0.001 *$ \\
\hline 3.Lubrication & $4.92(1.18)$ & $4.30(0.88)$ & $<0.001 *$ \\
\hline 4.Orgasm & $3.56(1.35)$ & $4.25(1.14)$ & $<0.001 *$ \\
\hline 5.Satisfaction & $3.71(1.24)$ & $4.30(0.90)$ & $<0.001 *$ \\
\hline 6.Pain & $4.60(1.32)$ & $4.66(1.23)$ & 0.226 \\
\hline $\begin{array}{l}\text { 7.Total sexual } \\
\text { function }\end{array}$ & $23.26(5.19)$ & $25.47(4.00)$ & $<0.001 *$ \\
\hline \multicolumn{4}{|l|}{ Condom Group } \\
\hline 1.Desire & $3.35(0.92)$ & $2.96(0.92)$ & $0.001 *$ \\
\hline 2.Arousal & $4.12(1.30)$ & $3.52(1.07)$ & $<0.001 *$ \\
\hline 3.Lubrication & $5.01(1.17)$ & $5.11(1.12)$ & $0.046^{*}$ \\
\hline 4.Orgasm & $4.08(1.31)$ & $3.53(1.30)$ & $<0.001 *$ \\
\hline 5.Satisfaction & $4.73(1.12)$ & $4.16(1.14)$ & $<0.001 *$ \\
\hline 6.Pain & $4.76(1.24)$ & $4.67(1.04)$ & 0.071 \\
\hline $\begin{array}{l}\text { 7.Total sexual } \\
\text { function }\end{array}$ & $25.96(4.98)$ & $24.04(4.77)$ & $<0.001^{*}$ \\
\hline
\end{tabular}

All the within group statistical analyses were performed using the Wilcoxon test.

$*(\mathrm{p}<0.05)$

\subsection{Comparison between Two Contraceptive Methods}

Table 2. Sexual function scores [mean (SD)] at recruitment in 2 groups of contraceptive methods

\begin{tabular}{|lccc|}
\hline \multicolumn{1}{|c}{$\begin{array}{c}\text { Sexual function } \\
\text { Domains }\end{array}$} & OCP & Condom & P-Value \\
\hline 1.Desire & $2.99(0.93)$ & $3.35(0.92)$ & $0 / 042^{*}$ \\
2.Arousal & $3.49(1.41)$ & $4.12(1.30)$ & $0.009^{*}$ \\
3.Lubrication & $4.92(1.18)$ & $5.01(1.17)$ & 0.654 \\
4.Orgasm & $3.56(1.35)$ & $4.08(1.31)$ & $0.034^{*}$ \\
5.Satisfaction & $3.71(1.24)$ & $4.73(1.12)$ & $<0.001 *$ \\
6.Pain & $4 / 60(1.32)$ & $4.67(1.04)$ & 0.881 \\
$\begin{array}{l}\text { 7.Total sexual } \\
\text { function }\end{array}$ & $23.26(5.19)$ & $25.96(4.98)$ & $0.002 *$ \\
\hline
\end{tabular}

All the between-group statistical analyses were performed using the Mann-Whitney U test

$*(\mathrm{p}<0.05)$ 
Table 3. Sexual function scores [mean (SD)] at 4 months follow up in 2 groups of contraceptive methods

\begin{tabular}{|cccc|}
\hline $\begin{array}{c}\text { Sexual function } \\
\text { Domains }\end{array}$ & OCP & Condom & P-Value \\
\hline 1.Desire & $3.83(0.74)$ & $2.96(0.92)$ & $<0.001^{*}$ \\
2.Arousal & $4.11(1.03)$ & $3.52(1.07)$ & $<0.001^{*}$ \\
3.Lubrication & $4.30(0.88)$ & $5.11(1.12)$ & $<0.001^{*}$ \\
4.Orgasm & $4.25(1.14)$ & $3.53(1.30)$ & $0.026^{*}$ \\
5.Satisfaction & $4.30(0.90)$ & $4.16(1.14)$ & 0.639 \\
6.Pain & $4.66(1.23)$ & $4.76(1.24)$ & 0.705 \\
7.Total sexual \\
function & $25.47(4,00)$ & $24.04(4.77)$ & 0.269 \\
\hline
\end{tabular}

All the between-group statistical analyses were performed using the Mann-Whitney U test

$*(\mathrm{p}<0.05)$

The comparison between the two contraceptive groups at recruitment and four months follow up is shown in tables 2 and 3. Table 2 indicates that at recruitment, four of the six domains, including desire $(\mathrm{p}=0.042)$, arousal $(\mathrm{p}=0.009)$, orgasm $(\mathrm{p}=0.034)$, satisfaction $(\mathrm{p}<0.001)$, and total sexual function scores $(\mathrm{p}=0.002)$ were higher in the condom group. At the follow-up three of the domains, including desire $(\mathrm{p}<0.001)$, arousal $(\mathrm{p}<0.001)$, and orgasm $(\mathrm{p}=0.026)$, were higher in OCP groups. Nonetheless, there was no significant difference between the two groups at follow-up for total sexual function score. However, sexual function in the OCP group improved clinically in comparison to the condom group (Table 3 ).

\section{Discussion}

Results indicated that excluding two of the domains, (lubrication and pain), there was an improvement in total sexual function after using OCPs LD and a reduction after using condoms. The enhancement of four domains of sexual function (desire, arousal, orgasm and satisfaction) and the total sexual function score in the OCP group, resulted in less fear of unwanted pregnancies and the reduction of blood loss and duration of menstruation as well as alleviation of menstrual complaints [20]. There was a previous study on 87 OCP users in the Chinese population which showed that three domains of sexual function (body image, satisfaction and sexual drive) might not be affected because of the multifaceted effects of OCPs [12]. Findings of Egarter et al.'s study among OCP users was similar with the current study. The study concluded that the absence of fear regarding unwanted pregnancies as well as other established advantages of OCPs, such as monthly cycle control, improved sexual function. [20]. However, Caruso et al. showed that desire and coital frequency reduced $(p<0.005)$ nine months after using OCPs, and sexual excitement decreased $(p<0.005)$ three months after using OCPs. The orgasm frequency did not show any changes during the use of OCPs $(\mathrm{p}=\mathrm{NS})$. Further, Caruso et al showed that the sexual enjoyment reduced at the third, sixth and ninth month of follow up $(p<0.001)$ [11]. The main reason for varying results between the current study and Caruso et al.'s study is the use of different dosages of OCPs in each research. The current study used LD with $30 \mu \mathrm{g}$ Ethinylestradiol and $150 \mu \mathrm{g}$ Levonorgestrol because this kind of OCPs is the most common one in Iran; Caruso et al. had used OCPs containing $15 \mu \mathrm{g}$ Ethinylestradiol and $60 \mu \mathrm{g}$ gestodene. Therefore, the different results are predictable because a low-dose of Ethinylestradiol may lead to decrease vaginal lubrication and a decrease in libido could be due to hypoandrogenism [11]. Women who used OCPs in Loeches et al.'s study reported a reduction in sexual desire [21], dissimilarity; could be due to demographic and cultural differences.

While condoms were not considered to have side effects or health risks, they were seen as less reliable and more difficult to use [13]. The reason for the reduction in sexual function scores in the condom group in the current study is most likely due to the cultural factors of Iranian societies. They believe that using condoms is difficult and unpleasant which has caused intermittent and incorrect usage. The results of this study confirmed the validity of the Oddens study as Oddens illustrated the main negative impact of condoms on all parameters of sexuality that has been measured (coital frequency, pleasure, sex drive, vaginal lubrication and over all influence on sex life) [11].

There were several retrospective studies in Iran regarding the effects of various contraception on quality of life and some domains of sexual function. However, these studies did not clarify all of the sexual function domains in details by using a Persian version female sexual function index. This study is the first prospective study in Iran about the effects of the two most common contraceptive methods on sexual function of Iranian women; thus, the discussion is restricted to compare similar studies in our country. The researchers concluded that condoms have significant adverse impacts on sexual function, and OCPs have positive effects on various domains of female sexual function. We recommend the future research with large sample size, and with three groups. The third group which does not use nor OCPs nor condoms for the sake of comparison. Also, researchers recommend the future research about the effects of various dosages of OCPs and other contraceptives on female sexual function in Iranian society.

\section{Acknowledgements}

This study as part of a M.S thesis was supported by Tehran University of Medical Sciences (grant No: 350). We would like to thank Dr. Hosseini Sadeh (Health and treatment centre of south of Tehran) and all Midwifes who assisted in data collection. We are grateful to Mr. Abbas Mehran from the school of Nursing and Midwifery, Tehran University of Medical Science, for his statistical advice. 


\section{REFERENCES}

[1] Nusbaum M, Rosenfeld JA. Sexual health across the lifecycle.Cambridge: Cambridge University Press, 2004.pp:11-19.

[2] Jahanfar S, Moulaienejad M. Sexual dysfunction booklet. Tehran: Bijeh pub, 2001. (book in Persian language)

[3] Lewis RW, Fugl-Meyer KS, Bosch R, et al. Epidemiology/Risk factors of sexual dysfunction. J Sex Med 2004; 1(1): 35-39.

[4] Safarinejad MR. Female sexual dusfunction in a population based study in Iran:revalence and associated risk factors. Int J Impot Res 2006;18(4):382-395.

[5] Trigwell P. Helping people with sexual problems: The clinical Importance of sexual dysfunction. London: Elsevier Health Sciences, 2005.

[6] Greco T, Graham CA, Bancroft J, Tanner A, Doll H. The effects of oral contraceptives on androgen levels and their relevance to premenstural mood and sexual interest: a comparison of two triphasics formulation containig norgestimate \& either 35 or $25 \mu \mathrm{g}$ of ethinylestradiol. Contraception 2007;76(1):8-17.

[7] Bancroft J, Sartorius N. The effects of Oral contraceptives on well-being and sexuality. Oxf Rev Reprod Biol 1990;12: 57-92.

[8] Graham CA, Ramos R, Bancroft J, Maglaya C, Farley TMM. The effects of steroidal contraceptives on the well-being and sexuality of women: a double-blind, Placebo-controlled, two-center study of combined and progestrone-only methods. Contraception 1995;52(6):363-369.

[9] Caruso S. Hormonal contraception and sexuality: The counseling before and during the pill intake. Giornale Italiano Di ostetricia e Ginecologia 2006;28(4):137-141.

[10] Bancroft J, Sherwin BB, Alexander GM, Davidson DW, Walker A. Oral contraceptives, androgens and sexuality of young women: The role of androgen. Arch Sex Behav 1991;20(2):121-135.

[11] Oddens BJ. Women's satisfaction with birth control: A publication survey of physical and psychological effects of oral contraceptives, Intra uterine Device, Condoms. Natural family planning and Sterilization Among 1466 women. Contraception 1999;59(5):277-286.

[12] Caruso S, Agnello C, Intelisano G, Farina M, Mari L, Cianci A. Sexual behavior of women taking low dose oral contraceptive containing $15 \mu \mathrm{g}$ ethinylestradiol/60 $\mu \mathrm{g}$ gestodene. Contraception 2004;69(3):237-240.

[13] Raymond HW, Sue ST, Dawn KG, et al. Impact of common contraceptive methods on quality of life and sexual function in Hong Kong Chinese women. Contraception 2004;70(6):474-482.

[14] Guida M, Di Spieziosardo A, Bramante S, et al. Effect of two types of hormonal contraception-oral versus intravaginal-on the sexual life of women and the partners. Hum Reprod J 2005;20(4):1100-1106.

[15] O'Connell k, Davis AR, Kerns J. Oral contraceptives: side effects and depression in adolescent girls. Contraception 2007;75(4):299-304.

[16] Niroomanesh S, Laimian M.Oral contraceptive: An effective method for prevention of pregnancy. Tehran:Arjmand pub, 1997. (book in Persian language)

[17] Anderson BA. Reproductive health: Women and Men's shared responsibility. Massachusetts: Jones and Bartlett 2004.

[18] Mohammadi K, Heydari M, Forutan K. The female sexual function index (FSFI) validation of the Iranian version. Payesh 2008; 7(3):269-278. (article in Persian language)

[19] Rosen R, Brown C, Heiman J, Leiblum S, Meston C, Shabsigh R. The female sexual function Index(FSFI): multidimentional self-Report Instrument for the assessment of female sexual function. J Sex Marital Ther 2000;26(2):191-208.

[20] Egarter C, Topcuoglu M, Imhof M, Hubert J. Low dose oral contraceptives and Quality of life. Contraception 1999;59(5):287-291.

[21] Loeches MM, Orti RM, Monfort M, Ortega E, Rius J.A, Comparative analysis of the modification of sexual desire of users of oral hormonal contraceptives and Intra uterine contraceptive Devices. The Europeon Journal of Contraception and reproductive Health care 2003; 8(3):129-134. 